\title{
Chemical resistance of polyphenylene sulfide needle
}

\author{
WenJun Doua ${ }^{a}$ Ruquan Zhang, Ying $\mathrm{Wu}^{+b}$ \\ School of Textile Science and Engineering, Wuhan Textile University, Wuhan, China 430200 \\ School of Economics, Wuhan Textile University, Wuhan, P.R. China, 430200 \\ a402968301@qq.com, b hellenying@wtu.edu.cn. \\ + Corresponding author. Tel: +86-18971590971 \\ E-mail address: hellenying@wtu.edu.cn.
}

\begin{abstract}
Keyword: needle non-woven material; filter non-woven material; polyphenylene sulfide; mechanical properties; orthogonal test

Abstract: The basic idea of this paper is to simulate use of the environment of high temperature filter material and study chemical resistance of needle-punched nonwoven fabric made from polyphenylene sulfide (PPS). An orthogonal test was designed to investigate the interaction effect of various factors, namely concentration of hydrochloric acid and sodium hydroxide, treatment time and treatment temperature, on the needle-punched nonwoven fabric. The concentration of hydrochloric acid and sodium hydroxide and treatment time were found to have important effects on mechanical property under the condition of 0.1 significant level. While needle-punched nonwoven fabric made from PPS was still keeping its excellent breaking strength, only less than the $10 \%$ drop under the condition of 24 hours in $12 \mathrm{~mol} / \mathrm{L}$ hydrochloric acid at $80^{\circ} \mathrm{C}$.
\end{abstract}

\section{Introduction}

A major role of nonwoven fabric in air filtration is to control air pollution, especially in high temperature filtration. The main high temperature filter material is to choose the organic material to suit the high temperature environment, including polyphenylene sulfide (PPS), aramid, polytetrafluoroethylene (PTFE) and polyimide (P84) ${ }^{[1]}$. The non-woven materials is made by spun-lace, needle-punched and other molding techniques with certain finishing methods, working in high-temperature dust-laden gas filtration such as chemical, petroleum, metallurgy, cement, waste incineration and other industrial production. A great number of studies have reported on filtration performance of fiber masses ${ }^{[2]}$. However, every little work has reported on service life of the high temperature material. In actual use process, flue gas composition is relatively complex, there are $\mathrm{SO}_{2}, \mathrm{SO} 3, \mathrm{NO}_{\mathrm{x}}$ and other alkaline tiny solid particles [3]. These industrial waste course a lot loss to the filter material ${ }^{[4]}$. In order to simulate use of the environment of high temperature filter material and study chemical resistance of needle-punched nonwoven fabric made from polyphenylene sulfide (PPS).An orthogonal test was designed to investigate the interaction effect of various factors, namely concentration of hydrochloric acid, treatment time and treatment temperature, on the needle-punched nonwoven fabric. It provides a new reference for PPS high temperature filter material more effective.

\section{Experiment}

Materials

The PPS needle-punched non-woven fabric samples were prepared using production line 
machineries in industry and the fibres having average fineness of 2.2 dtex and length of $51 \mathrm{~mm}$ were used for the present study; hydrochloric acid (A. R.).

Methods

One of the most common methods of experimental design is to vary the selected parameters to be studied one at a time, keeping all the other parameters constant. This type of study is quite useful in understanding the effect of the varied selected parameters, but this technique has a major drawback. In this type of study, the trend of response was observed [5]; while varying the selected parameters at a fixed level of other parameters, the effect may not be same at other levels of fixed parameters ${ }^{[6]}$. If the experiments are carried out on a multivariable approach, then it is quite possible to study the individual and interactive effects of the chosen variables ${ }^{[7]}$. To study the effect of the concentration of the acid, temperature and treatment time on the fabric properties, experiments were designed as factorial design for three variables. The actual values of the three variables corresponding to coded levels are given in Table land Table 2 respectively.

Table 1 the acid resistance factor levels coding table

\begin{tabular}{|c|c|c|c|c|}
\hline \multirow{2}{*}{\multicolumn{2}{|c|}{ level }} & \multicolumn{3}{|c|}{ factors } \\
\hline & & $\begin{array}{l}\text { A the concentration / } \\
(\mathrm{mol} / \mathrm{L})\end{array}$ & B temperature/ $\left({ }^{\circ} \mathrm{C}\right)$ & $\mathrm{C}$ treatment time $/(\mathrm{h})$ \\
\hline 1 & & 14.5 & 60 & 3 \\
\hline 2 & & 2.8 & 70 & 12 \\
\hline \multirow[t]{2}{*}{3} & & 1.35 & 80 & 24 \\
\hline & \multicolumn{4}{|c|}{ Table 2 the acid resistance orthogonal experiment scheme } \\
\hline \multirow[b]{2}{*}{$\begin{array}{l}\text { The } \\
\text { number }\end{array}$} & \multirow{2}{*}{ experiment } & \multicolumn{3}{|c|}{ factors } \\
\hline & & $\begin{array}{l}\text { A the concentration / } \\
(\mathrm{mol} / \mathrm{L})\end{array}$ & B temperature/ $\left({ }^{\circ} \mathrm{C}\right)$ & $\mathrm{C}$ treatment time / $(\mathrm{h})$ \\
\hline 1 & & 1 & 1 & 1 \\
\hline 2 & & 1 & 2 & 2 \\
\hline 3 & & 1 & 3 & 3 \\
\hline 4 & & 2 & 1 & 2 \\
\hline 5 & & 2 & 2 & 3 \\
\hline 6 & & 2 & 3 & 1 \\
\hline 7 & & 3 & 1 & 3 \\
\hline 8 & & 3 & 2 & 1 \\
\hline 9 & & 3 & 3 & 2 \\
\hline
\end{tabular}

\section{Results and discussion}

Figure 1 and figure 2 show the SEM image of untreated PPS needle-punched nonwoven samples.

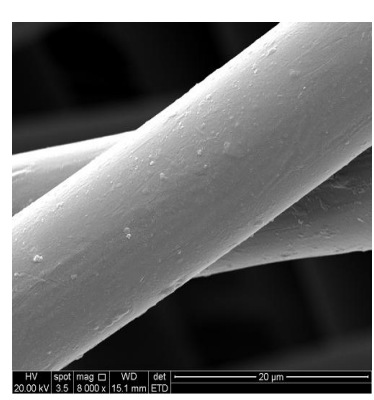

Figure 1 SEM image $(\times 8000)$ of untreated samples

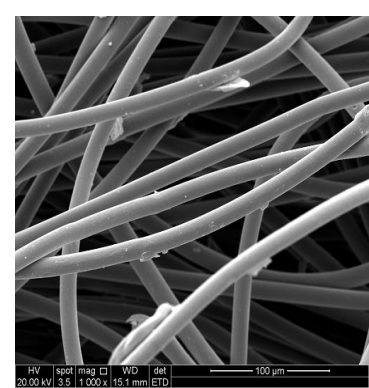

Figure 2 SEM image $(\times 1000)$ of untreated samples

649 


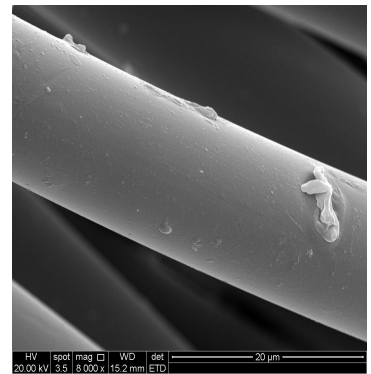

Figure 3 SEM image $(\times 8000)$ of acid treatment samples

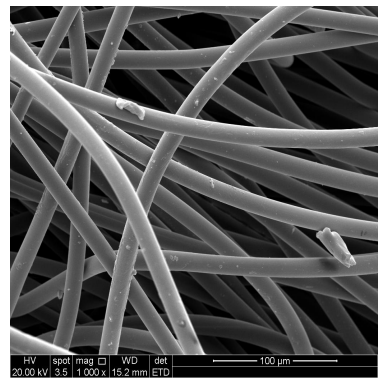

Figure 4 SEM image $(\times 1000)$ of acid treatment samples

Acid resistance test results analysis

Figure 3 and figure 4 show the SEM image of acid-treated PPS needle-punched nonwoven samples. Comparing figure 3 with figure 1 , it can be seen that there is significant damage to the fiber surface, but no significant change in fiber diameter, comparing figure 4 with figure 2 , it can be seen that the spacing between fibers becomes large, reducing the contact between the fibers.

The mechanical properties of PPS needle-punched nonwovens acid resistance test and analysis of variance, the results shown in Table 3.

Table 3 Results of orthogonal experiment

\begin{tabular}{|c|c|c|c|c|}
\hline $\begin{array}{l}\text { The } \\
\text { experiment } \\
\text { number }\end{array}$ & $\begin{array}{l}\text { Elongation at } \\
\text { break / (\%) }\end{array}$ & $\begin{array}{l}\text { Breaking } \\
\text { strength } /(\mathrm{N})\end{array}$ & $\begin{array}{l}\text { The areal } \\
\text { density /( } \mathrm{g} / \mathrm{m} 2)\end{array}$ & $\begin{array}{l}\text { Thickness } \\
/(\mathrm{mm})\end{array}$ \\
\hline 1 & 20.0 & 900 & 544.3 & 3.12 \\
\hline 2 & 22.0 & 875 & 541.8 & 3.41 \\
\hline 3 & 21.5 & 859 & 542.0 & 3.48 \\
\hline 4 & 21.9 & 1012 & 554.5 & 3.28 \\
\hline 5 & 21.5 & 1053 & 551.3 & 3.50 \\
\hline 6 & 22.4 & 1095 & 545.6 & 3.59 \\
\hline 7 & 22.1 & 942 & 556.8 & 3.61 \\
\hline 8 & 20.0 & 900 & 544.3 & 3.12 \\
\hline 9 & 22.0 & 875 & 541.8 & 3.41 \\
\hline
\end{tabular}

** idicates a degree of influence on indicators of the factors in the significant level $\mathrm{a}=0.1$ condition it is significant, in which $\mathrm{a}=0.1, \mathrm{~F}(2,2)=9$.

Table 4 Analysis of variance

\begin{tabular}{lcclcc}
\hline $\begin{array}{l}\text { Sources of } \\
\text { variance }\end{array}$ & $\begin{array}{c}\text { Bias } \\
\text { squares }\end{array}$ & variance & $\begin{array}{l}\text { Deviation } \\
\text { from the } \\
\text { mean of } \\
\text { sum of } \\
\text { squares }\end{array}$ & F & \\
& & & & \\
\hline A & 46230.67 & 2 & 23115.36 & 374.85 & $* *$ \\
B & 1455 & 2 & 727.5 & 11.80 & $*$ \\
C & 5876.67 & 2 & 2938.34 & 47.65 & $*$ \\
Error e & 123.33 & 2 & 61.66 & & \\
The sum & 53685.67 & 8 & & & \\
\hline
\end{tabular}

PPS needle-punched nonwovens samples' breaking strength decreases with the increasing concentration of hydrochloric acid. Comparing figure land figure 3 , it can be seen that the interval between the fibers becomes larger, contact between the fibre becomes less. Under the corruption of hydrochloric acid, the contact and friction between the fibers reduce, resulting PPS needling-punched nonwovens samples' breaking strength with increasing concentration of 
hydrochloric acid decreases. In hydrochloric acid solution, while the fiber surface has obvious damage, but material can still keep more than $75 \%$ of the highest breaking strength in concentrated hydrochloric acid. This is because the presence of benzene ring structure of PPS fiber molecular formula, whose benzene ring of PI bond energy is high, $619 \mathrm{KJ} / \mathrm{mol}$, not easy to break. This is the reason why the PPS fiber has excellent chemical resistance to avoid to be corrupted. However, benzene and sulfur molecules linked together, bond energy is relatively lower, $271 \mathrm{KJ} / \mathrm{mol}$, the benzene ring meta position is opened easily by oxidants causing chemical reaction, which will destroy the molecular structure of the PPS fiber. However concentrated hydrochloric acid is not the oxidizer. It's the oxygen in an acid environment that oxides the benzene ring meta position leading to the destruction of the material and mechanical properties, rather than the corrosion of the hydrogen ion directly. Namely PPS needle-punched nonwoven material has good acid resistance.

\section{Conclusions}

Needle-punched nonwoven fabric made from PPS still kept its excellent breaking strength, only less than the $10 \%$ drop under the condition of 24 hours in $12 \mathrm{~mol} / \mathrm{L}$ hydrochloric acid at $80^{\circ} \mathrm{C}$. Concentration of hydrochloric acid has a significant impact on breaking strength of PPS Needle-punched nonwoven samples.

\section{Acknowledgements}

The support of the project was sponsored by Hubei Province Natural Science Fund Project(Project number: 2013CFA090). We express our sincere gratitude to them.

\section{Reference}

[1] Wang C,Lin H,cen Y Y. Study on the preparation of steady-state chitosan nanoparticle as silk-fabric finishing agent [J]. Advanced Material Research. 2011.175: 745-749.

[2] Honghong Yi, Jiming Hao, Lei Duan. Fine particle and trace element emissions from an anthracite coal-fired power plant equipped with a bag-house in China[J]. Fuel, 2007, 11: 2050-2057.

[3] Fuping Qian, Hmgang Wang. Retracted: Study of the filtration performance of a plain wave fabric filter using response surface methodology[J].Journal of Hazardous Materials, 2010, 176(1-3): 559-568.

[4] Rajesh D. Anandjiwala, Lydia Boguslavsky. Development of Needle-punched nonwoven fabrics from flax fibers for air filtration applications[J].Textile Research Journal, 2008, 78(7): 614-624.

[5] G. E. P. Box, D. W. Behnken. Some new three level designs for the study of quantitative variables [J]. Technometrics, 1960, 2(4):455-475.

[6] V. K. Kothari, A. Das. The Compressional Behaviour of Spunbonded Nonwoven Fabrics [J]. Journal of the Textile Institute, 1993, 84(1):16-30.

[7] Filter media endure tough conditions, Membrane Technology, 2005.11:25-36. 